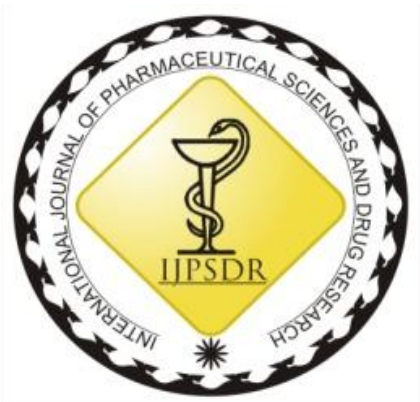

\author{
RESEARCH ARTICLE
}

ISSN: 0975-248X CODEN (USA): IJPSPP

$(\mathrm{cc})$ EY-NC-SA

\title{
Development of an Oxcarbazepine Solid Dispersion Using Skimmed Milk to Improve the Solubility and Dissolution Profile
}

\author{
M. Shah, D. Patel* \\ Department of Pharmaceutics, Parul Institute of Pharmacy and Research, Faculty of Pharmacy, Parul University, A/P: \\ Limda, Tal: Waghodiya, Dist. Vadodara, Gujarat, India
}

Copyright (C) 2019 M. Shah et al. This is an open access article distributed under the terms of the Creative Commons Attribution-NonCommercialShareAlike 4.0 International License which allows others to remix, tweak, and build upon the work non-commercially, as long as the author is credited and the new creations are licensed under the identical terms.

\begin{abstract}
Oxcarbazepine has low solubility and low oral bioavailability, so it's a challenge to formulate suitable dosage form. In this present investigation, to improve the dissolution rate and solubility, skimmed milk is used as a carrier. Physical mixers were prepared using various drugs to carrier ratio and spray drying technology was used to develop solid dispersion with the carrier. Various techniques were used to characterize the solid dispersion immediately after they were made which includes differential scanning calorimetry, scanning electron microscopy, fourier transform infrared spectroscopy, X-ray diffraction and in-vitro dissolution profiles. The differential scanning calorimetry thermograms of raw drug indicated of its anhydrous crystalline nature. In thermograms of solid dispersion, the characteristic peak was absent suggesting the change from crystalline nature to amorphous form. X-ray diffraction confirmed those results. X-ray diffraction results of raw drug showed highly intense peak characteristic of its crystalline nature where solid dispersion showed less intense, more diffused peak indicating the change in crystalline form. Fourier transforms infra-red spectroscopy studies showed there was no interaction between drug and carrier. Scanning electron microscopy support the amorphous nature of mixer. The whole formulation showed distinct enhancement in the drug release behavior and solubility. The optimum oxcarbazepine to skimmed milk ratio 1:3 enhances the in-vitro drug release by 3.5 fold and also show distinct increase in solubility. It was concluded that for improvement of solubility of poorly water soluble oxcarbazepine, skimmed milk powder as a carrier can be utilize very well.
\end{abstract}

Keywords: Skimmed milk, Solid dispersion, Solubility, Multimedia Dissolution.

DOI: 10.25004/IJPSDR.2019.110509

Int. J. Pharm. Sci. Drug Res. 2019; 11(5): 204-209

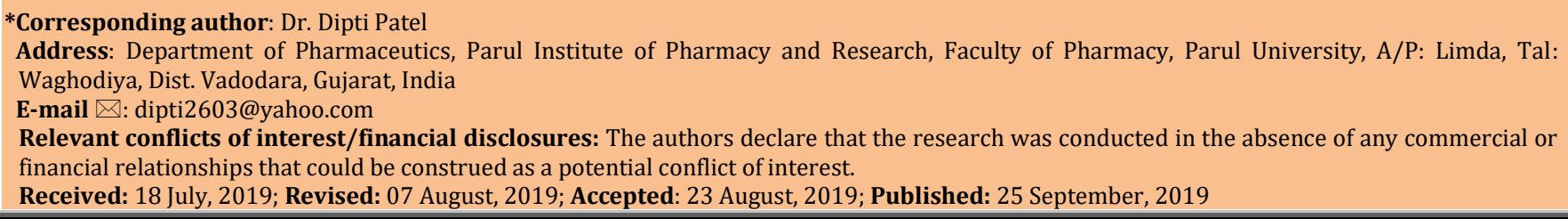

\section{INTRODUCTION}

Epilepsy disease has a massive range of symptoms developed by different cerebral disorders. The disease is classified as generalized or partial epilepsy. [1] 10-keto analogue of carbamazepine is known as oxcarbazepine, the antiepileptic drug that is first line drug for treatment of partial onset seizures. Even though, the efficacy of oxcarbazepine seems to be Carbamazepine. [2] Oxcarbazepine is a novel antiepileptic drug, which is used in treatment of epilepsy for adults and pediatric patients. ${ }^{[3]}$ It's associated with BCS class II, therefore it has low solubility and its dissolution is the rate-limiting 
step for absorption. Oxcarbazepine is completely absorbed and extensively metabolized to its pharmacologically active 10-monohydroxy metabolite, where oxcarbazepine has half-life of $2 \mathrm{~h}$ and its metabolite has a half-life of 9 h. [4]

Drugs with poor aqueous solubility are an important issue for pharmaceutical research scientists. [5] In pharmaceutical world from last few eras, more number of poorly soluble drug substances are growing constantly. Consequently, many new approaches have been addressed to improve the solubility and enhance the dissolution rates. [6] So, the challenge for the development scientists is to use various solubilization technologies. For preparation of solid dispersion (SD), commonly used methods include the fusion or solvent processes such as hot melt extrusion, spray drying, solvent co-precipitation and super critical fluid process. [7-9] For the formulation of poorly water soluble drug, $\mathrm{SD}$ is established as a firm platform. A successful SD should be simply converted to ultimate dosage form and it must be physically and chemically stable during storage. Development of poor water soluble drug as SD officiating a distinct enhancement in their dissolution rates and is generally assisted by an enhancement in their relative bioavailability. [10]

The advantages of SD method are simple method and its non toxicity. Till now no efforts has been done to prepare SD using skimmed milk. Skimmed milk is very cheap, freely available, biodegradable and it does not show any toxicity issue. So the formulation of SD of oxcarbazepine with the use of skimmed milk and restricted water solubility may be a prospective and cost effective way to overwhelm the issue. Skimmed milk used as a carrier in formulation of solid is the best approach for modulating gastric irritation as well as enhancement of the water solubility of the Oxcarbazepine. [11]

In this investigative study, Oxcarbazepine poorly aqueous soluble drug used to enhance the dissolution profile and solubility by using SD method and skimmed milk as a carrier. Casein micelles, lipoprotein particles and globular proteins are the fraction portion of the carrier skimmed milk. [12] The $\alpha$-s1, $\alpha-s 2, \beta$-casein and $\kappa$-casein are the principal fraction of casein whereas, amphiphilic $\beta$-casein act as a detergent molecule which has surfactant property. The whey proteins are also a part of skimmed milk which has principle fractions of $\beta$-lactoglobulin, bovine serum albumin, immunoglobulins, and a-lactalbumin. [13] These whey proteins were found to be more surface active. These molecules have a predominant solubility than that of caseins. Formulations are evaluated by $\mathrm{X}$ ray diffraction (X-RPD), differential scanning calorimetry (DSC), scanning electron microscopy (SEM) analysis and fourier transform infra-red spectroscopy (FTIR).

\section{MATERIALS AND METHODS} Materials
The gift sample of oxcarbazepine was obtained from Gowrie Research Pvt. Ltd, Vadodara (Gujarat, India). Other excipients and solvents used to prepare formulation were of analytical grade.

Development of skimmed milk powder [14]

$100 \mathrm{ml}$ of skimmed milk measured accurately and it was spray dried at $140^{\circ} \mathrm{C}$ inlet temperature, $90^{\circ} \mathrm{C}$ outlet temperature and $5 \mathrm{ml} / \mathrm{min}$ flow rate using spray drier (labultima, India). The free flowing powder obtained from $100 \mathrm{ml}$ of milk was about $8.9^{*} \mathrm{~g}$ powder $\left({ }^{*}\right.$ mean of three experiments) and these powder passed through a sieve \# 65 and for further use powder was stored in well tight container.

Development of Physical mixer (PM) [15]

Oxcarbazepine and skimmed milk were weigh and mixed uniformly in ratios of 1:1, 1:1.5, 1:2, 1:2.5, 1:3 and 1:3.5. Mortar and pestle was used to mix it thoroughly. The obtained physical mixtures were place for $72 \mathrm{~h}$ in a desiccator over calcium chloride solution at room temperature and then it was passed through \#65 sieves. For further use powder was stored in well tight container.

\section{Development of SD [16]}

Oxcarbazepine SD with carrier skimmed milk powder in varying proportion of 1:1, 1:1.5, 1:2, 1:2, 1:2.5, 1:3 and 1:3.5 were prepared by spray drying method. Specific drug to carrier proportion was taken. In ethanol the oxcarbazepine was dissolved and in another beaker contains water where skimmed milk carrier was dissolved. This solution was sonicate for $20 \mathrm{~min}$. The solution was spray dried in a labultima spray drier at $140^{\circ} \mathrm{C}$ inlet temperature, $90^{\circ} \mathrm{C}$ outlet temperature and 5 $\mathrm{ml} / \mathrm{min}$ flow rate. The resultant free flowing powder was store in proper tight container for future use.

Saturation solubility studies [17-18]

According to the reported method by Hecq et al, saturation solubility studies were conducted. Raw oxcarbazepine, SD and PM formulations carry equivalent amounts of oxcarbazepine were placed in a flask containing water $+0.3 \%$ sodium dodecyl sulfate (SDS), $0.1 \mathrm{~N} \mathrm{HCl}$ and Phosphate buffer $\mathrm{pH}$ 6.8. Obtain specimen were placed on a shaker and agitated at $37 \pm$ $0.5^{\circ} \mathrm{C}$ for $48 \mathrm{~h}$ until equanimity was attained. These aliquots were filtered through $0.45 \mu \mathrm{m}$ nylon membrane filter. Appropriately samples were diluted. UV-visible spectrophotometer was used for assayed against a blank (Shimadzu, India).

Determination of drug content [19]

The SD and PM equivalents to $150 \mathrm{mg}$ of oxcarbazepine were dissolved independently in $20 \mathrm{~mL}$ of water and shake for $15 \mathrm{~min}$ than add $30 \mathrm{ml}$ of methanol, sonicate the solution or $15 \mathrm{~min}$ and the $0.3 \%$ SDS was for make up the volume. The obtain solution was filtered and further diluted. The prepare samples were filtered through a $0.45 \mu \mathrm{m}$ nylon membrane filter and the spectrophotometric method used to determine drug content at $254 \mathrm{~nm}$. As oxcarbazepine formulation, blank formulation was also treated it used to reduce the intervention of protein present in skimmed milk. 


\section{DSC analysis [20]}

DSC determination of the oxcarbazepine drug, skimmed milk powder and its formulation was recorded on PerkinElmer 4000. Software used for DSC analysis was PYRIS version- 11.1.0.0488, 2009, Perkin Elmer, Inc. Sample around $1 \mathrm{mg}$ was heated at around $30-350^{\circ} \mathrm{C}$ temperature and heating rate was $10^{\circ} \mathrm{C} / \mathrm{min}$. Analyzed under a nitrogen atmosphere on an aluminum pan under nitrogen purging and flow rate was $20 \mathrm{ml} / \mathrm{min}$.

\section{FTIR spectral analysis}

FTIR spectra of moisture free pure oxcarbazepine powder, Skimmed milk and formulations were obtained using a FTIR spectrophotometer using $\mathrm{KBr}$ as a reference. The scanning range was $400-4000 \mathrm{~cm}^{-1}$ (Shimadzu 8400s).

SES analysis
The surface morphology of raw oxcarbazepine, SD and PM product were scrutinized by scanning electron microscope (Phillips (FEI) ESEM-XL-30 TMP). The samples were fasted on a brass stub using double sided tape and then gold coated in vacuum by a sputter coater, the picture were then taken.

XRD analysis

X-ray diffraction design of oxcarbazepine, skimmed milk powder, SD and PM was recorded with an X-ray diffractometer (Shimadzu, Maxima XRD- 7000) under conditions of " $\mathrm{Cu}$ " radiation target having nickel filter, $30 \mathrm{~mA}$ current.

\begin{tabular}{ccc}
\multicolumn{3}{l}{ Table 1: Pure oxcarbazepine solubility in various solvents } \\
\hline S. No. & Solvent & Solubility \pm SD (mg/ml) \\
\hline 1 & Water & $0.085 \pm 0.005$ \\
2 & Water $+0.3 \%$ SDS & $0.238 \pm 0.013$ \\
3 & 0.1 N HCl & $0.087 \pm 0.003$ \\
4 & Phosphate buffer 6.8 & $0.080 \pm 0.004$ \\
\hline
\end{tabular}

Table 2: Drug content and solubility of PM AND SD

\begin{tabular}{|c|c|c|c|c|c|c|}
\hline $\begin{array}{l}\text { S. } \\
\text { No. }\end{array}$ & Code & Ratio & Drug content \pm SD $\%$ & $\begin{array}{c}\text { Solubility in Water + 0.3\% } \\
\text { SDS } \pm \text { SD mg/ml }\end{array}$ & $\begin{array}{l}\text { Solubility in } 0.1 \mathrm{~N} \mathrm{HCl} \pm \\
\mathrm{SD} \mathrm{mg} / \mathrm{ml}\end{array}$ & $\begin{array}{c}\text { Solubility in Phosphate } \\
\text { buffer } 6.8 \pm S D \mathrm{mg} / \mathrm{ml}\end{array}$ \\
\hline 1 & OSPM 1 & $1: 1$ & $98.62 \pm 0.61$ & $0.569 \pm 0.007$ & $0.090 \pm 0.006$ & $0.083 \pm 0.003$ \\
\hline 2 & OSPM 2 & $1: 1.5$ & $100.20 \pm 0.21$ & $0.636 \pm 0.013$ & $0.103 \pm 0.014$ & $0.099 \pm 0.005$ \\
\hline 3 & OSPM 3 & $1: 2$ & $97.56 \pm 0.06$ & $0.689 \pm 0.018$ & $0.153 \pm 0.024$ & $0.136 \pm 0.001$ \\
\hline 4 & OSPM 4 & $1: 2.5$ & $98.66 \pm 0.12$ & $0.734 \pm 0.017$ & $0.199 \pm 0.005$ & $0.156 \pm 0.003$ \\
\hline 5 & OSPM 5 & $1: 3$ & $98.74 \pm 0.16$ & $0.746 \pm 0.012$ & $0.211 \pm 0.019$ & $0.189 \pm 0.002$ \\
\hline 6 & OSPM 6 & $1: 3.5$ & $96.34 \pm 0.10$ & $0.752 \pm 0.013$ & $0.235 \pm 0.018$ & $0.210 \pm 0.025$ \\
\hline 7 & OSSD 1 & 1:1 & $96.24 \pm 0.16$ & $0.698 \pm 0.005$ & $0.264 \pm 0.021$ & $0.221 \pm 0.006$ \\
\hline 8 & OSSD 2 & $1: 1.5$ & $97.41 \pm 0.25$ & $0.726 \pm 0.016$ & $0.326 \pm 0.024$ & $0.303 \pm 0.037$ \\
\hline 9 & OSSD 3 & $1: 2$ & $98.15 \pm 0.10$ & $0.816 \pm 0.019$ & $0.493 \pm 0.018$ & $0.419 \pm 0.018$ \\
\hline 10 & OSSD 4 & $1: 2.5$ & $97.54 \pm 0.08$ & $0.722 \pm 0.027$ & $0.596 \pm 0.028$ & $0.501 \pm 0.010$ \\
\hline 11 & OSSD 5 & $1: 3$ & $99.87 \pm 0.19$ & $0.999 \pm 0.016$ & $0.788 \pm 0.023$ & $0.688 \pm 0.08$ \\
\hline 12 & OSSD 6 & $1: 3.5$ & $97.87 \pm 0.04$ & $0.993 \pm 0.024$ & $0.789 \pm 0.010$ & $0.673 \pm 0.011$ \\
\hline
\end{tabular}

\section{In vitro dissolution [21]}

In In-vitro dissolution study oxcarbazepine equivalent to $150 \mathrm{mg}$ were added to $900 \mathrm{~mL}$ of $0.1 \mathrm{~N} \mathrm{HCl}$, intestinal fluid $\mathrm{pH}$ 6.8, and distilled water + 0.3\% SDS at $37 \pm 0.5^{\circ} \mathrm{C}$ and a rotation speed of $60 \mathrm{rpm}$ using USP type II dissolution apparatus (Paddle type). Aliquot was withdrawn at specific time intervals of 5, 10, 20, 30, 45, 60, $90 \mathrm{~min}$ and replaced by fresh dissolution media to maintain sink condition. The samples were analyzed by UV spectroscopy at $254 \mathrm{~nm}$. Percent cumulative drug release versus time profiles was plotted. The triplicate study was done for each formulation.

\section{RESULTS AND DISCUSSION}

\section{Drug content and Solubility profiles}

The main objective of SD is to enhance the solubility and hence the dissolution rate of poorly soluble oxcarbazepine drug. Raw drug solubility study is shown in table 1. Oxcarbazepine drug content and solubility data of PM and SD is shown in table 2 . According the data it has shown that the drug content in the formulated SD and PM is in the range of $\pm 5 \%$ of theoretical amount, recommended the method used for the formulation as satisfactory and reproducible. Raw oxcarbazepine was found to have saturation solubility in distilled water $+0.3 \%$ SDS was $0.085 \pm 0.005 \mathrm{mg} / \mathrm{ml}$. The solubility was intensify to $0.999 \pm 0.0016 \mathrm{mg} / \mathrm{ml}$ using SD technique and the solubility of PM was increased to $0.0746 \pm 0.012 \mathrm{mg} / \mathrm{ml}$. Solubility enhancement of oxcarbazepine was likely due to particle size reduction and formation of amorphous state. In case of PM better solubility was due to surface active agent and amino acid content of milk. The improve solubility is responsible because hydrophilic casein micelles entrap the oxcarbazepine. The analysis suggests that skimmed milk was capable to improve the solubility of poorly water soluble oxcarbazepine drug.

\section{In vitro dissolution}

The multimedia dissolution profiles of raw drug, SD and PM are exhibited in figure 1. Raw drug exhibited dissolution of only $43.19 \% \pm 1.23$ within $90 \mathrm{~min}$ in water $+0.3 \%$ SDS. The dissolution of PM formulations was $67.56 \% \pm 1.18$ within 90 min where a SD formulation was $98.45 \% \pm 0.62$ within 90 min in water + $0.3 \%$ SDS. It was higher than the raw the raw oxcarbazepine drug. Batch OSSD 5 and OSPM 6 show highest dissolution was $98.45 \%$ and $67.56 \%$ respectively. It is perceptible that the dissolution study improves with enhancing amount of carrier. However, above drug carrier ratio 1:3.5 in the SD the dissolution rate plunged and in PM 1:3.5 rate of dissolution increase is very low. The enhanced solubility and dissolution evince by SD can be elucidated by the 
formation of porous and fluffy particle by spray drying method. Higher surface free energy and higher surface area enhanced the dissolution rate of drug. The SD mixer showed high amount of dissolution rate as compare to PM. Moreover, presence of carrier prevents aggregation of drug particle and improves the dissolution. Wetting property of carrier has higher influence on dissolution. Carrier skimmed milk also having surfactant property, which decreased the interfacial tension between drug oxcarbazepine and dissolution medium, gives better dissolution. Aqueous solubility of oxcarbazepine enhance due to the hydrophilic casein micelles entrap the drug. Therefore OSSD 5 and OSPM 6 were selected for future studies.
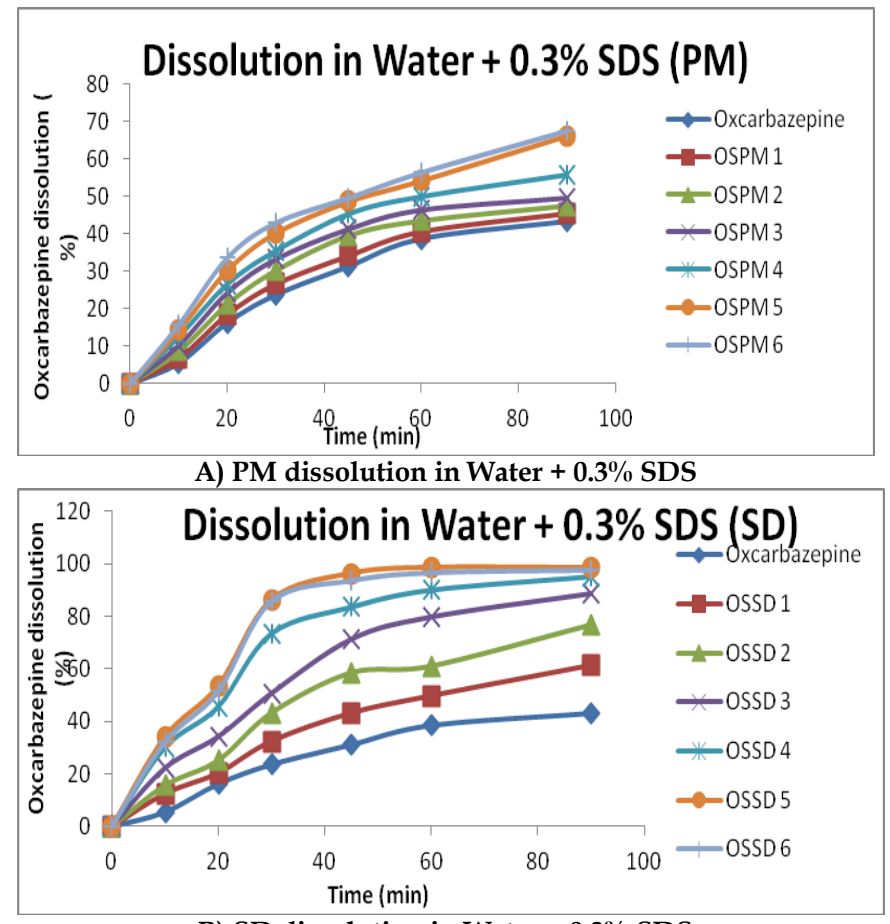

B) SD dissolution in Water + $0.3 \%$ SDS

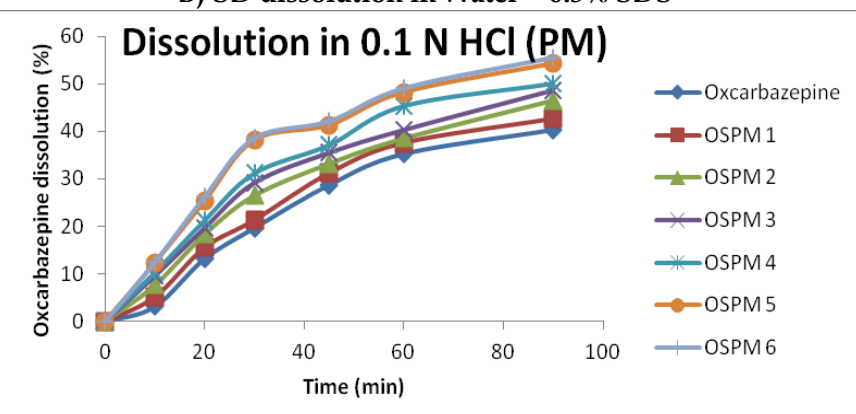

C) PM dissolution in $0.1 \mathrm{~N} \mathrm{HCl}$

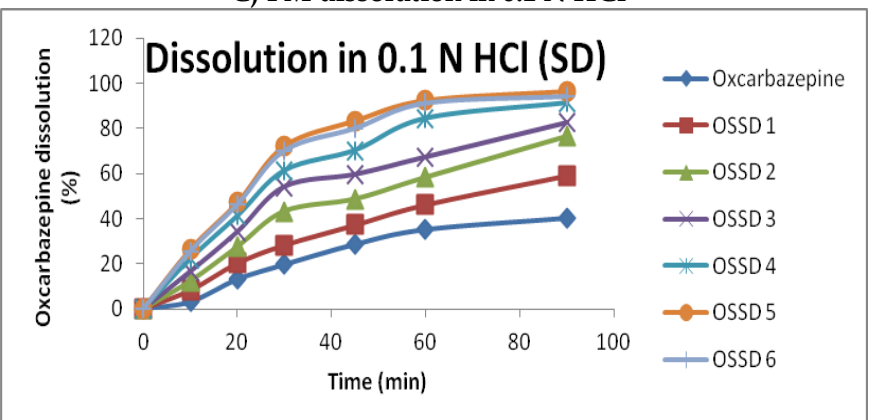

D) SD dissolution in $0.1 \mathrm{~N} \mathrm{HCl}$

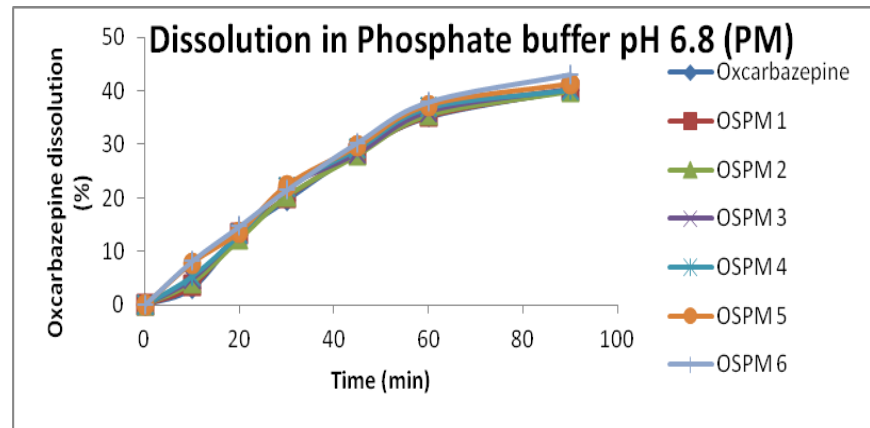

E) PM dissolution in Phosphate buffer pH 6.8

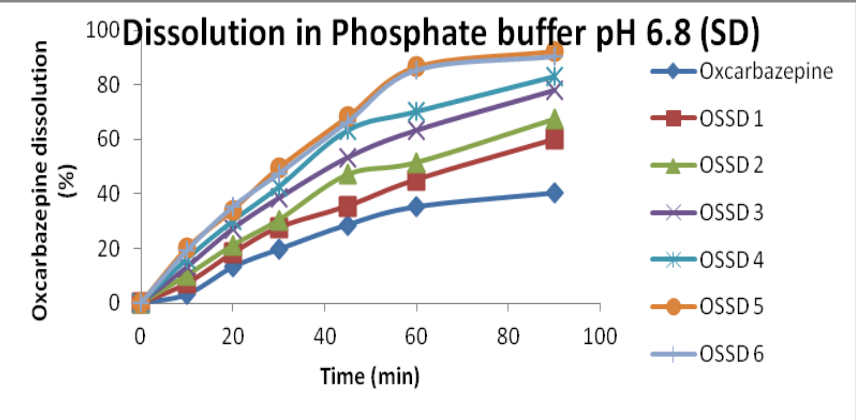

F)SD dissolution in Phosphate buffer pH 6.8

Fig. 1: In vitro dissolution profiles of Oxcarbazepine PM and SD in multimedia

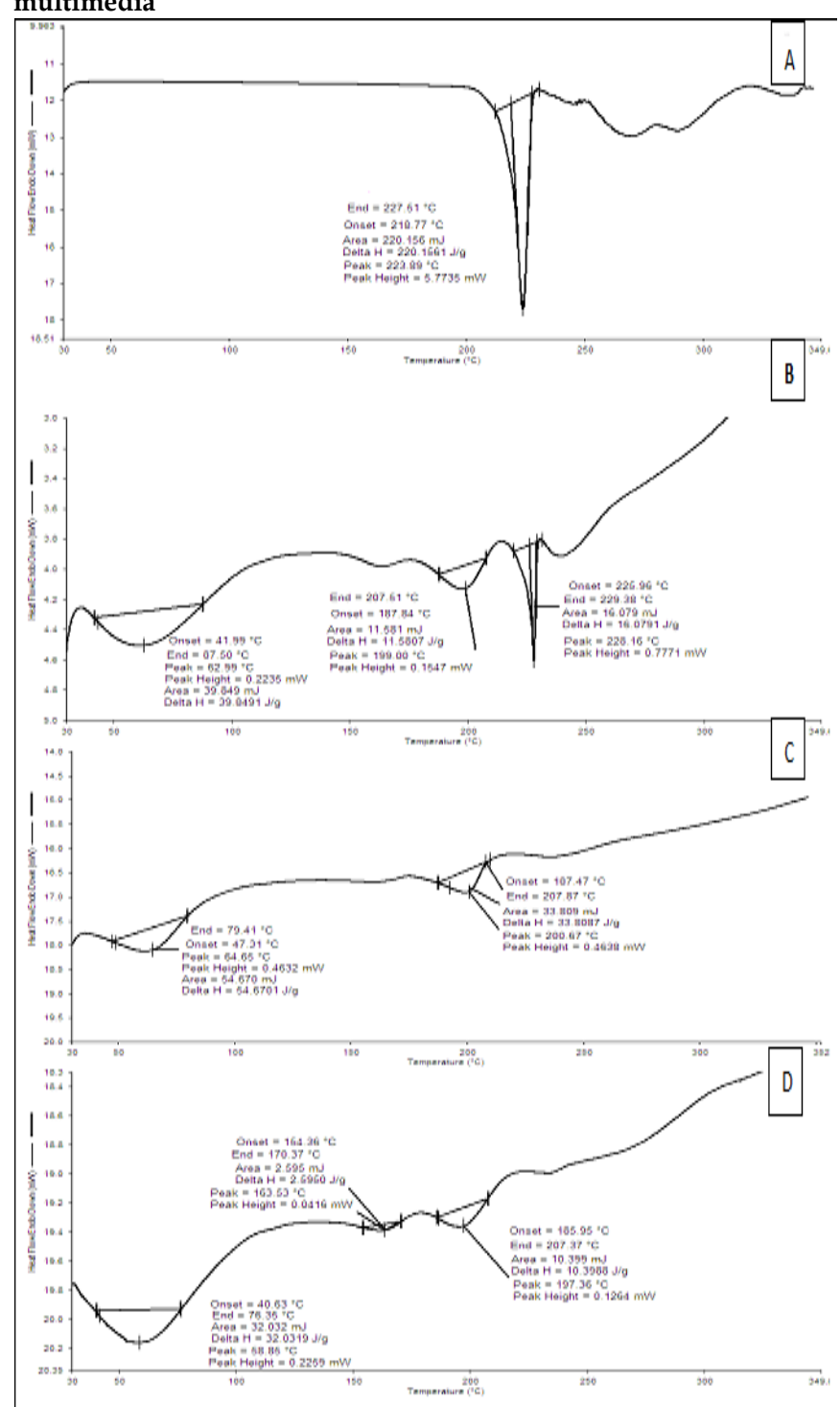

Fig. 2: DSC thermograms of Oxcarbazepine (A), OSPM 6 (B), OSSD 5 (C) and Skimmed milk (D) 


\section{Solid state characterization}

Solid state properties of the process were scrutinized by the means of DSC, XRD and SEM.

\section{DSC thermograms}

DSC has been important key tool in characterization of solid skimmed milk powder and drug oxcarbazepine. The thermograms are shown in figure 2; it was analyzed by investigating the endothermic transition profile and peak temperature. The DSC curve oxcarbazepine indicate endothermic peak at $223.09^{\circ} \mathrm{C}$ commensurate to its melting point that specify the crystalline nature of drug indicated in figure 2 (A). The skimmed milk evinced characteristic endothermic peak at $58.85^{\circ} \mathrm{C}$ and $197.36^{\circ} \mathrm{C}$ elucidate the amorphous nature of skimmed milk indicated in figure 2 (D). The thermograms of OSPM 6 showed blend of skimmed milk and drug peaks indicated in figure 2 (B). On the contrary, drug peak is not present in OSSD 5 thermograms enlighten, the drug has interacted with carrier that is skimmed milk and has converted to amorphous nature indicated in figure 2 (C).

\section{XRD spectra}

Figure 3 shows X-ray of oxcarbazepine, Skimmed milk, PM and SD. In present study it was observed that in PM diffraction patterns were summation of oxcarbazepine and skimmed milk with alike sharp peaks with alike $d$ values. In SD the study showed changes in peak position, disappearance of many peak and lowering of relative peak intensity. On the other hand $d$ values of SD were completely different from oxcarbazepine and skimmed milk. The study further showed that the crystalline peaks in diffractograms of $\mathrm{SD}$ were wider and decreased intensities which indicate amorphous nature of the drug in SD. This analysis accordance with those investigated in DSC study.

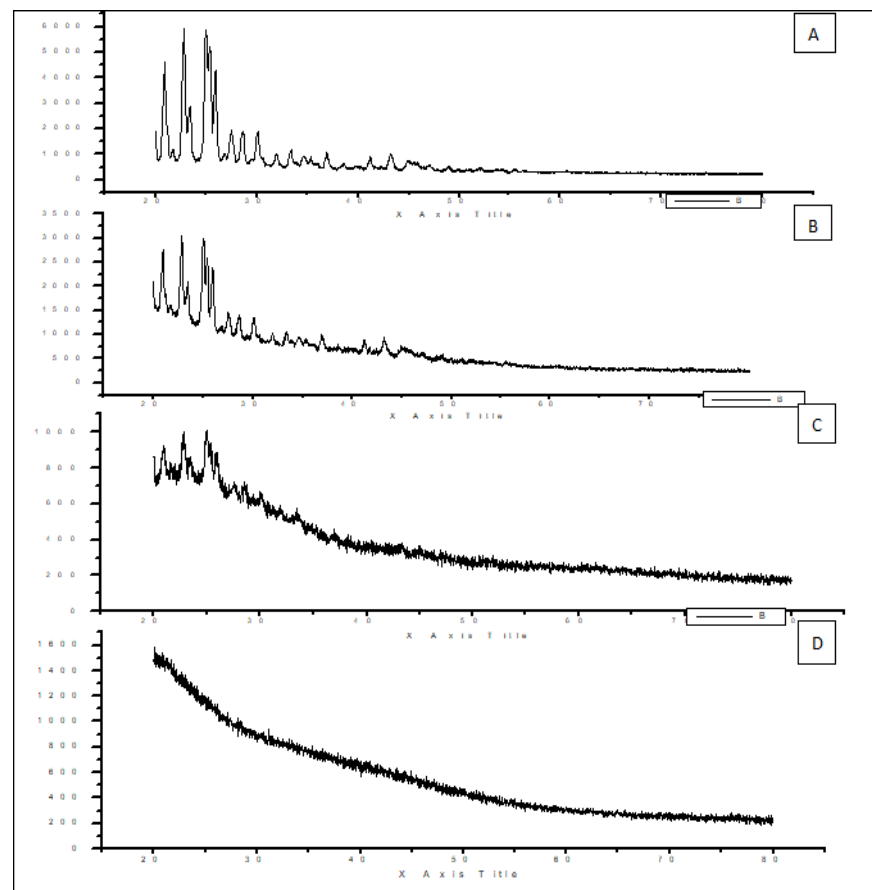

Fig. 3: XRD of Oxcarbazepine (A), OSPM 6 (B), OSSD 5 (C) and Skimmed milk (D)

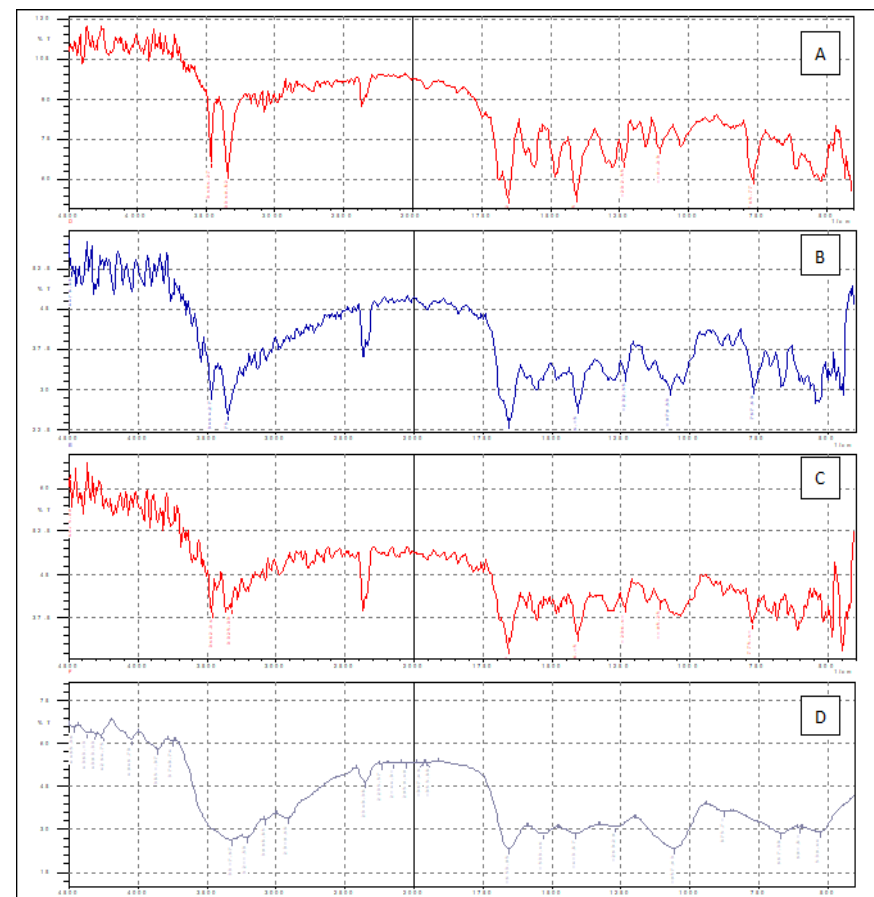

Fig. 4: FTIR spectra of Oxcarbazepine (A), OSPM 6 (B), OSSD 5 (C) and Skimmed milk (D)
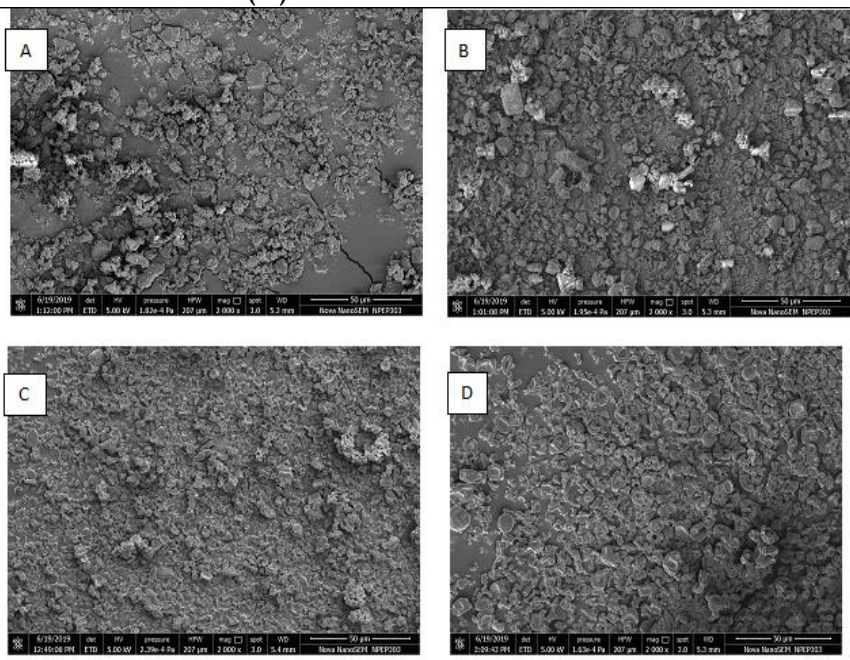

Fig. 5: SEM of Oxcarbazepine (A), OSPM 6 (B), OSSD 5 (C) and Skimmed milk (D)

\section{FTIR spectra}

The FTIR spectra of samples were given in figure 4 . FITR spectra of oxcarbazepine evince characteristic peaks of $\mathrm{C}-\mathrm{H}$ bending, $\mathrm{O}-\mathrm{H}$ bending, C-N stretching, C$\mathrm{N}$ vibrations, $\mathrm{C}=\mathrm{C}$ stretching, $\mathrm{C}-\mathrm{H}$ stretching, $-\mathrm{NH}$ stretching at 765.77, 1101.39, 1232.55, 1406.15, 1651.12, $3340.82,3464.27$ wave number respectively. In the spectra of OSSD 5 formulation, the characteristic peak of SKM were present at nearly same positions and oxcarbazepine peaks were also present but at a lessen rate of absorption indicate carrier entrap the drug. None of the spectra showed any peak other than drug and SKM recommended absences of chemical interaction.

SEM analysis

The microscopic results of oxcarbazepine, PM and SD were done by SEM analysis as shown in given figure 5 . Oxcarbazepine show crystalline surface where, the 
surface morphology of PM divulge largely amorphous and some crystals of drug but SD was in form of amorphous state. DSC and XRD results have been confirmed by the SEM analysis results and it confirmed formulation of SD.

In conclusion, the present study investigations suggested the probability of preparation of an SD of oxcarbazepine with skimmed milk by spray drying technology. Oxcarbazepine converted to amorphous form, from crystalline one. The DSC, XRD and SEM studies indicated formulation of SD which significantly enhanced the solubility and dissolution profile of drug.

\section{ACKNOWLEDGEMENTS}

The authors thank Gowrie Research PVT Ltd, Vadodara, for providing oxcarbazepine drug as a gift samples for present investigation. They also would like to thank parul institute of pharmacy and research, parul university, Vadodara, for providing essential facilities to carry out the research work.

\section{REFERENCES}

1. Carrozzino D, Marchetti D, Laino D, Minna M, Verrocchio MC, Fulcheri M, Verrotti A, Bech P. Anxiety in adolescent epilepsy. A clinimetric analysis Nord J Psychiatry. 2016; 70(6):424-429.

2. Koch MW, Polman SK. Oxcarbazepine versus carbamazepine monotherapy for partial onset seizures. Cochrane Database Syst Rev. 2009: 7(4):CD006453.

3. Tzitiridou M, Panou T, Ramantani G, Kambas A, Spyroglou $\mathrm{K}$, Panteliadis C. Oxcarbazepine monotherapy in benign childhood epilepsy with centrotemporal spikes: a clinical and cognitive evaluation. Epilepsy Behav. 2005;7(3):458-467.

4. Wellington K, Goa KL. Oxcarbazepine: an update of its efficacy in the management of epilepsy. CNS Drugs. 2001; 15(2):137-163

5. Di L, Paul V, Takashi M. Bridging solubility between drug discovery and development. Drug Discov Today. 2012; 17(910):486-495

6. Wlodarski K, Sawicki W, Paluch KJ, Tajber L, Grembecka M, Hawelek L, Wojnarowska Z, Grzybowska K, Talik E, Paluch $M$. The influence of amorphization methods on the apparent solubility and dissolution rate of Tadalafil. Eur. J. Pharm. Sci. 2014; 62:132-140

7. Thayer AM. Finding solutions, Custom manufacturers take on drug solubility issues to help pharmaceutical firms move products through development. Chem Eng News. 2010; 8:1318.

8. Miller DA, McConville JT, Yang W, Williams RO, McGinity JW. Hot-melt extrusion for enhanced delivery of drug particles. J Pharm Sci. 2007; 96(2):361-376.

9. Chauhan B, Shimpi S, Paradkar A. Preparation and evaluation of glibenclamide-polyglycolized glycerides solid dispersions with silicon dioxide by spray drying technique. Eur. J. Pharm. Sci. 2005; 26:219-230.

10. Sugimoto M, Okagaki T, Narisawa S, Koida Y, Nakajima K. Improvement of dissolution characteristics and bioavailability of poorly water-soluble drugs by novel cogrinding method using water-soluble polymer. Int J Pharm. 1998; 160:11-19.

11. Dickinson E, Stainsby G. Advances in Food Emulsion and Foams. Elsevier Applied Sciences, London, 1988.

12. Sahin NO, Arslan H. Inclusion complex of prednisolone with skimmed milk. Part I: physicochemical characterization. 2007; 127(8);1255-1261.

13. Topaloğlu Y, Yener G, Gönüllü U. Inclusion of ketoprofen with skimmed milk by freeze-drying. Il Farmaco.1999; 54(10):648-652.

14. Agrawal AM, Mayur S, Patel AD, Raikes MS. Characterization and performance assessment of solid dispersions prepared by hot melt extrusion and spray drying process. Int. J. Pharm. 2013; 457(1):71-81.

15. Hadjira R, Jumah Masoud MS, Eltayeb SE, Narimane L, Jie Z, Qineng PI. Carbamazepine solubility enhancement in tandem with swellable polymer osmotic pump tablet: A promising approach for extended delivery of poorly water-soluble drugs. Asian J. Pharm. 2014; 9(3):146-154.

16. Wlodarski K, Tajber L, Sawicki W. Physicochemical properties of direct compression tablets with spray dried and ball milled solid dispersions of tadalafil in PVP-VA. Eur J Pharm Biopharm. 2016; 109:14-23.

17. Lu M, Xing H, Yang Z, Ding P. Dissolution enhancement of tadalafil by liquisolid technique. Pharma Dev Tech. 2016; 10(5):1-13

18. Hecq J, Deleers M, Fanara D, Vranckx H, Amighi $K$. Preparation and characterization of nanocrystals for solubility and dissolution rate enhancement of nifedipine. Int. J. Pharm. 2005; 299(1-2):167-177.

19. Buchi N, Nalluri S. Vidyasagar, Maheswari KM. Effect of Excipients on Oxcarbazepine Release from Modified Release Matrix Tablets. J Appl Pharm Sci. 2012; 2(8); 150-158.

20. Patel TB, Soni TG, Suhagia BN. Preparation and characterization of oxcarbazepine microemulsion. Egypt Pharmaceut J. 2016; 15:173-80.

21. Philippsen FRZ, Falcao BR, Teixeira LM, Sausen TR Development and validation of a dissolution method for a BCS class IV drug - tadalafil. IJAPA. 2017; 07(02):10-15.

HOW TO CITE THIS ARTICLE: Shah M, Patel D. Development of an Oxcarbazepine Solid Dispersion Using Skimmed Milk to Improve the Solubility and Dissolution Profile. Int. J. Pharm. Sci. Drug Res. 2019; 11(5): $204-209$. DOI: 10.25004/IJPSDR.2019.110509 